\title{
Takotsubo cardiomyopathy: A review of literature on clinical status and meta-analysis of diagnosis and medical therapy
}

\author{
Aref Albakri* \\ St-Marien hospital Bonn Venusberg, Department of internal medicine, Bonn, Germany
}

\begin{abstract}
Takotsubo (stress) cardiomyopathy (TCM) or transient LV apical ballooning syndrome is recently discovered heart muscle disease characterized by transient LV dysfunction not explained by coronary artery disease (CAD). Although it has a relatively favorable prognosis, it is an important cause of heart failure. Its pathophysiologic mechanisms remain poorly understood, and its diagnosis and clinical management lacks standardized guidelines. The aim of the current review is to combine research findings and advance clinical knowledge and understanding on Takotsubo cardiomyopathy including its diagnosis and clinical management.
\end{abstract}

\section{Introduction}

Takotsubo cardiomyopathy is a recently described cardiac condition with a reversible form of left ventricular contractile dysfunction (akinesia or hypokinesia). However, a precise understanding of its demographics, clinical features, etiology, prognosis and clinical management remains tenuous. This paper presents a systematic review of published literature on Takotsubo cardiomyopathy with an emphasis on its clinical description, epidemiology, risk factors, clinical presentation, prognosis, pathophysiology, diagnosis and clinical management. The objective is to expand the current knowledge and understanding of research status of Takotsubo cardiomyopathy and relevance to diagnosis and clinical management.

\section{Clinical description}

\section{Historical context}

The seminal mention of Takotsubo cardiomyopathy (TCM) in medical literature was made in Japan by Iga, et al. [1] in 1989, who reported a clinical case of a cardiac syndrome with a Takotsubolike appearance characterized by a reversible form of left ventricular (LV) dysfunction associated with Pheochromocytoma. However, the study did not refer to the reversible cardiac condition as "Takotsubo" cardiomyopathy but concluded that high circulating catecholamine could have a damaging effect on the myocardium. A year later in 1990, Sato, et al. [2] described this reversible form of cardiomyopathy as Takotsubo-like LV dysfunction. However, studies outside of Japan variously referred to this reversible myocardial condition as transient apical ballooning syndrome [3], stress cardiomyopathy [4] or ampulla cardiomyopathy [5]. Since 1991, several case reports and small series have described affected patients in Japan [5-8] and in Caucasian populations in Europe and North America [9].

\section{Clinical definition}

Takotsubo cardiomyopathy - also known as transient LV apical ballooning syndrome in relation to balloon-like abnormalities involving the LV apex - has been defined as a cardiac syndrome characterized by transient or reversible LV dysfunction with electrocardiographic (ECG) abnormalities mimicking acute myocardial infarction (MI) and with minimal release of myocardial enzymes in the absence of demonstrable obstructive coronary artery disease (CAD) [6]. The principal characteristic of TCM is LV dysfunction taking the shape of Takotsubo, a medieval Japanese pot that has a round bottom and narrow neck used for trapping octopuses (Figure 1).

In TCM, dysfunction is shaped like Takotsubo pot. The left-most (end-diastolic phase) and middle (end-systolic phase) images show left ventriculogram in the right anterior oblique projection. The extensive apical area reveals akinesia and the basal segment hypercontraction imminent in the end-diastolic phase. The right-most image shows the Japanese Takotsubo port with a round bottom and narrow neck, which resembles the shape of LV dysfunction in Takotsubo cardiomyopathy [10].

\section{Types of TCM}

Four types pf TCM can be revealed using LV angiograms obtained in the right anterior oblique view (30 degrees) during diastole and systole [11] (Figure 2). Templin, et al. [11] assessed clinical features of 1,750 TCM patients and identified four types of TCM based on the location of LV wall motion abnormalities. The four types are apical, mid-ventricular, basal and focal TCM. Apical TCM is the most common, found in $81.7 \%$ of the total patients (Panel A and B) followed by mid-ventricular in $14.6 \%$ of the patients (Panel C and D). Basal and focal types are the least common found in $2.2 \%$ (Panel E and F) and $1.5 \%$ (Panel G and $\mathrm{H}$ ) of the total TCM patients respectively.

${ }^{*}$ Correspondence to: Aref Albakri, St-Marien hospital Bonn Venusberg, Department of internal medicine, Bonn, Germany, E-mail: arefalbakri@yahoo.com

Key words: takotsubo cardiomyopathy, transient LV apical ballooning syndrome, stress cardiomyopathy

Received: June 21, 2018; Accepted: June 26, 2018; Published: June 30, 2018 

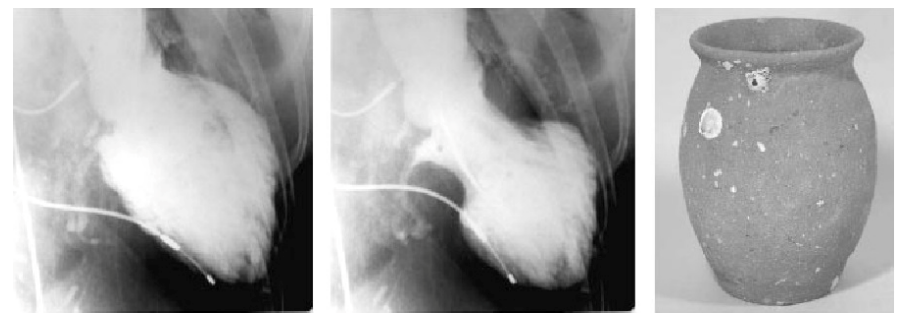

Figure 1. Takotsubo Cardiomyopathy and Takotsubo Port [10]

Left Ventriculogram at end-diastole phase (lef panel) end-systolic phase (middle panel) in anterior oblique projection. Area around the apex reveals akinesia and basal segments reveal hypercontraction at end-diastolic phase. Right panel is a picture of Japanese Takotsubo with a round bottom and narrow neck

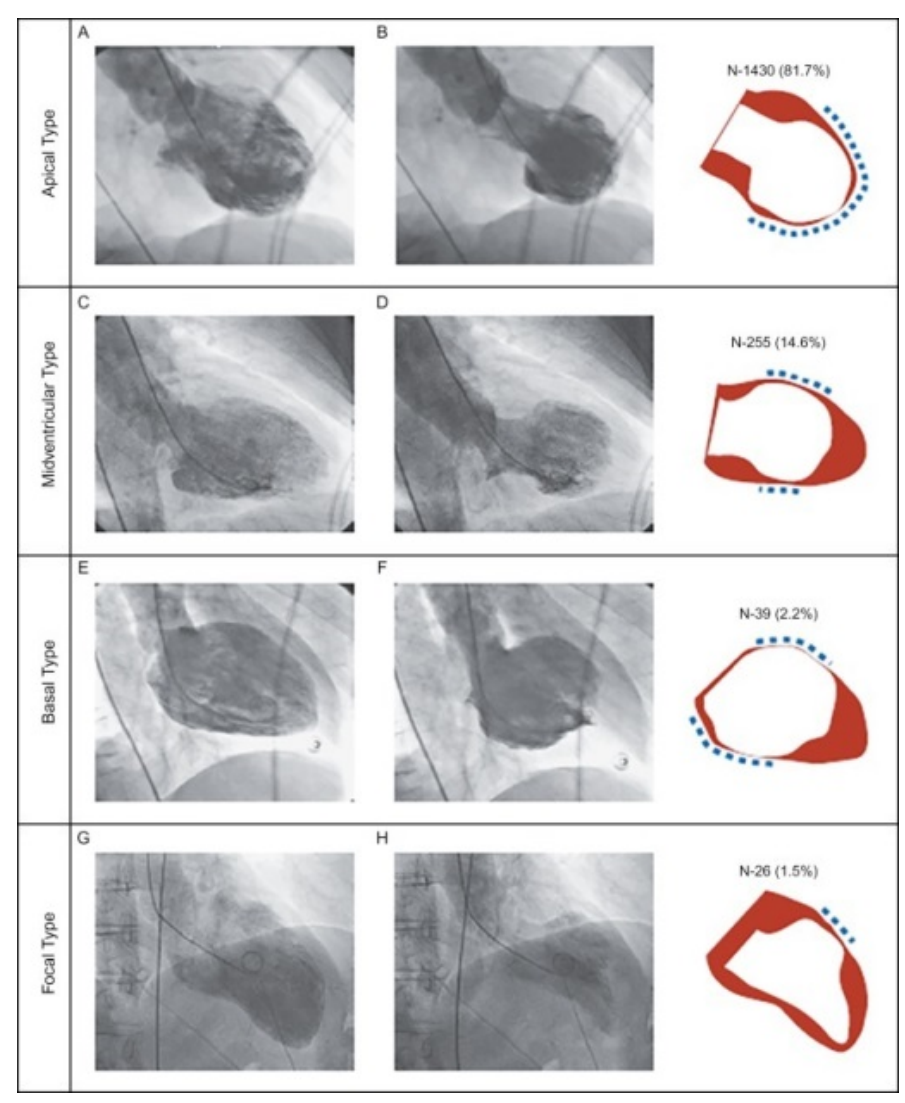

Figure 2. Types of Takotsubo Cardiomyopathy [11].

LV angiograms obtained at right anterior oblique view during diastole (left panel) and systole (middle panel). The right panel shows wall motion abnormalities: red indicates diastole; white indicates systole; and dashed line indicates the location of wall motion abnormalities. The four types of Takotsubo cardiomyopathy based on their location are apical (Panel A and B), mid-ventricular (Panel C and D); basal (Panel E and F) and focal (Panel $\mathrm{G}$ and $\mathrm{H}$ ).

\section{Epidemiology}

Takotsubo cardiomyopathy is a recently identified form of cardiomyopathy lacking large-scale epidemiological studies. However, a rapid increase in published case reports and series between 1989 and 2007 analyzed in a systematic review of Takotsubo literature in SCOPUS and MEDLINE databases provide important insights into its prevalence in defined populations [12]. Although Gianni, et al. [13] systematic analysis of TCM literature reports that TCM may account for between $1 \%$ and $2 \%$ of suspected cases of acute myocardial infarction (AMI), the true prevalence is not fully understood [13].
Four early small case series [3,14-16] in the U.S. and Japan assessed the prevalence of TCM among consecutive patients presenting with suspected acute coronary syndrome (ACS). Bybee, et al. [3] investigation of TCM in the U.S. between 2002 and 2003 report it accounted for about $2.2 \%$ of ST-segment elevation acute coronary syndrome (ACS). Three Japanese case series on TCM [14-16] report the prevalence of TCM at $1.7 \%$ [14], 2.2\% [15] and $2.0 \%$ of the cases presenting with a sudden onset of heart failure (HF) and abnormal Q-waves or ST-T changes suggesting acute myocardial infarction. [16].

\section{Risk factors}

Research on risk factors for TCM is still evolving. However, comparing demographic and co-morbid predictors of TCM with that of MI on 24,701 patients between 2008 and 2009, El-Sayed and associates [17] observed the female gender is an important risk factor for developing TCM affecting $89.0 \%$ of women compared to $38.9 \%$ of women with myocardial infarction. Akashi, et al. [10] added that TCM occurs predominantly in post-menopausal women following exposure to sudden and unexpected physical and/or emotional stress. Incidents of TCM increased significantly in elderly women residing near the epicenter of Niigata earthquake, a source of acute emotional and physical stress [18]. White race residing in wealthier neighborhood also have higher incidents of TCM compared to MI patients. TCM patients are also more likely to have a history of cerebrovascular accidents, substance abuse, anxiety disorders, chronic liver disease and sepsis [10]. However, it is Komamura, et al. [19] in a review of literature on TCM who categorized the main risk factors for developing TCM into three, namely (a) lack of estrogen; (b), acute emotional or physical stress; and (c) genetic factors.

\section{Lack of estrogen}

Accumulating research evidence is demonstrating that the lack of estrogen is an important risk factor for developing TCM. In particular, postmenopausal women who generally have reduced estrogen levels account for more than $90 \%$ of TCM patients [19]. Kuo, et al. [20] reported hormone replacement therapy had a beneficial protective effect against the development of TCM. In the study, none of the 31 women diagnosed with TCM had received estrogen replacement therapy compared to those without TCM who had received the therapy. Further, Ueyama, et al. [21] observed ovariectomized rats subjected to restraint stress had a greater decrease in LV function compared to rats receiving estradiol (hormone) supplementation therapy. The study explained that myocytes express estrogen receptors alpha and beta. Migliore, et al. [22] added that estrogen increases the transcription of cardio-protective factors such as heat-shock protein and atrial natriuretic peptide, which protects against cardiotoxicity that may result from catecholamine toxicity, calcium overload and reduced oxidative stress.

\section{Emotional/Physical Stress}

Emotional or physical stress is another key risk factor for developing TCM, such that, some studies have used the term stress cardiomyopathy instead of TCM [19]. Supporting evidence demonstrates that incidents of TCM are higher in the aftermath of a devastating natural disaster such as in the widely mentioned case of Japan after the Niigata earthquake. The association of natural disasters to the development of TCM have been linked to the implication of natural disasters as a key source of acute emotional and physical stress [18]. There are also supporting reports of a high prevalence of mood disorders and use of antidepressants among TCM patients [23]. Patients with depressive disorders experiencing stressful events have decreased vagus nerve 
tension and increased response to adrenal medullary hormones thought to contribute to the development of TCM [24]. Finally, some TCM patients with depressive disorders may exhibit elevated levels of noradrenaline extravasation [25].

\section{Genetic factors}

The relationship between genetic factors and TCM is still evolving. Zaroff, et al. [26] associated certain polymorphisms of alpha- and betaadrenergic receptors with hibernating myocardium, which occurs as a symptom of subarachnoid bleeding and has physiopathology similar to that of TCM. Whereas specific adrenergic receptor polymorphism in TCM patients are yet to be identified, TCM patients were observed to have a higher frequency of L41Q polymorphism of G-protein coupled receptor kinase (GRK5) compared to control group [27]. Further, L41Q polymorphism GRK5 responds to catecholamine stimulation and weakens the response of beta-adrenoreceptors, which may lead to balloon dilation of LV due to negative inotropic effect or beta-adrenoreceptors decoupling [27]. These reports suggest that genetic factors may play a partial role in increasing susceptibility to TCM in some patients. However, additional studies are warranted to demonstrate the role of genetic factors in the pathophysiology of TCM.

\section{Clinical presentation}

Several prospective and retrospective case series $[3,4,7,12,18,28$ 31] (Table 1) have reported the most frequently encountered clinical and laboratory features of TCM. There is a consensus among the nine summarized case series demonstrating a clear gender discrepancy, with the female gender having a disproportionately high percentage, ranging between $80 \%$ [29] and $100 \%$ [3] of the total reported cases. In all the reported cases, exposure to unexpected emotional or physical stress such as death in the family or abuse precedes the onset of TCM. The most frequently cited clinical symptoms of TCM on admission are chest pain and dyspnea, which mimics that of acute myocardial infarction (AMI) [18,28-30].

The most commonly cited electrocardiography (ECG) findings on admission are ST-segment elevation in precordial leads, subsequent T-wave inversion and pathological Q-wave formation. However, they are inadequate for a confirmatory diagnosis because of inability to distinguish between TCM and acute myocardial infarction [3]. Furthermore, most cases of TCM do not have significant coronary stenosis but have higher levels of serum catecholamine and plasma brain natriuretic peptide (BNP) whose secretion mimics that of myocardial infarction [32]. Other important clinical features but uncommon include a slight increase in cardiac enzyme creatinine kinase and troponin, and basal hyperkinesia [33]. Case series [3,4,7,12,28-31] on clinical and laboratory features report the most commonly occurign features are preceding stress, chest pain, ST-segment elevation, Q-waves, LVEF, LV reversal, pulmonary edema, provocative multivessle spasm (Table 1).

\section{Prognosis}

Although TCM has a generally favorable prognosis compared to other forms of cardiomyopathy, there have been some reported cases of fatal complications, most importantly, LV free wall rapture [34]. The most devastating and common clinical complication of TCM is heart failure in the presence or absence of pulmonary edema but current published hospital mortality data seems to under-represent the occurrence of TCM-associated heart failure. Templin et al. [11] reports death rate from any cause and major advance cardiac events at $5.6 \%$ and $9.9 \%$ respectively per patient-year. Hemodynamics of the acute phase of TCM has usually been associated with that of New York Heart Association (NYHA) Class III heart failure but has not received sufficient research attention to demonstrate the association [28]. Takotsubo cardiomyopathy also has very low reported rates of recurrence $>10 \%$ (Table 1). However, specific understanding of the pathophysiologic mechanisms underlying the recurrence of TCM remains incompletely understood [10].

\section{Pathophysiology}

The exact pathophysiology of TCM remains vaguely understood. However, a majority of patients undergoing myocardial biopsy share several similar clinical findings including (a) interstitial infiltrates made up of lymphocytes, leukocytes and macrophages; (b) myocardial fibrosis; and (c) contraction bands in the presence or absence of overt myocyte necrosis [10]. These inflammatory changes and contraction

Table 1. Case Series on Clinical and Laboratory Features of Takotsubo Cardiomyopathy

\begin{tabular}{|c|c|c|c|c|c|c|c|c|c|}
\hline Feature /Study Description & $\begin{array}{c}\text { Bybee, } \text { et } \\
\text { al. }[3]\end{array}$ & $\begin{array}{c}\text { Sharkey, et } \\
\text { al. }[4]\end{array}$ & $\begin{array}{c}\text { Kurisu, et } \\
\text { al. [7] }\end{array}$ & $\begin{array}{c}\text { Kurowski, et } \\
\text { al. }[12]\end{array}$ & $\begin{array}{c}\text { Sato, et al. } \\
\quad[18]\end{array}$ & $\begin{array}{c}\text { Akashi, } \text { et al. } \\
{[28]}\end{array}$ & $\begin{array}{c}\text { Yoshida, et } \\
\text { al. [29] }\end{array}$ & $\begin{array}{c}\text { Wittstein, et } \\
\text { al. }[30]\end{array}$ & $\begin{array}{c}\text { Tsuchihashi, } \\
\text { et al. } \text { [31] }\end{array}$ \\
\hline Sample size & 16 & 22 & 30 & 35 & 16 & 13 & 15 & 19 & 88 \\
\hline Country & U.S. & U.S. & Japan & Germany & Japan & Japan & Japan & US & Japan \\
\hline Mean Age & 71 & 65 & 70 & 72 & 71 & 73 & 72 & 61 & 67 \\
\hline Female (\%) & 100 & 91 & 93 & 94 & 94 & 85 & 80 & 95 & 86 \\
\hline Preceding stressor (\%) & 44 & 14 & 17 & 42 & 100 & 69 & 40 & NS & 43 \\
\hline Chest pain (\%) & 69 & 91 & 67 & NS & 100 & 54 & 87 & 95 & 67 \\
\hline ST-segment elevation (\%) & 81 & 59 & 100 & 69 & 56 & 92 & 87 & 11 & 90 \\
\hline Q-waves (\%) & 31 & 45 & NS & NS & NS & NS & 7 & 37 & 27 \\
\hline Baseline mean LVEF (\%) & 40 & 29 & 49 & 50 & 49 & 42 & 43 & 20 & 41 \\
\hline Follow-up LVEF (\%) & 60 & 63 & 69 & 68 & 66 & 65 & 76 & 60 & 64 \\
\hline LV reversal period (days) & 8 & 24 & 11 & NS & 18 & 17 & 11 & 21 & NS \\
\hline Pulmonary edema (\%) & 44 & 0 & 3 & NS & 6 & 0 & NS & 16 & 22 \\
\hline Intra-aortic balloon pump (\%) & 6 & 18 & 0 & NS & 0 & 15 & 7 & 16 & 8 \\
\hline Coronary stenosis $>50 \%(\%)$ & 0 & 0 & 0 & 0 & 0 & 0 & NS & 5 & 0 \\
\hline Normal coronary arteries by angiography (\%) & 25 & 100 & 83 & 0 & 100 & 100 & 100 & 95 & NS \\
\hline Spontaneous multi-vessel spasm & 0 & NS & 10 & 0 & 0 & 0 & 0 & 0 & 0 \\
\hline Provocative multi-vessel spasm (\%) & NS & 43 & 43 & 0 & 0 & 0 & 17 & NS & 10 \\
\hline In-hospital mortality (\%) & 0 & 0 & 0 & 9 & 0 & 8 & 0 & 0 & 1 \\
\hline Recurrence (\%) & 6 & 9 & 0 & 6 & NS & 0 & NS & 0 & 3 \\
\hline
\end{tabular}

NS: Not Stated 
bands help to differentiate TCM from coagulation necrosis observed in myocardial infarction (MI) in the setting of coronary artery occlusion. Several concepts have been advanced to explain the distinctive contractile pattern observed in a majority of TCM patients. The common ones are as follows: (a) Multi-vessel epicardial coronary artery spasm; (b) Coronary microvascular impairment; (c) Catecholamine cardiotoxicity; and (d) Neurogenic stunned myocardium.

\section{Multi-vessel epicardial coronary artery spasm}

Regionally hibernating myocardium in the setting of epicardial coronary artery spasm and has been proposed as a possible pathological mechanism of reversible myocardial dysfunction, which is the distinguishing characteristic of TCM. In the absence of spontaneous coronary spasm, impaired coronary circulation due to vulnerable plaque rapture has also been suggested to contribute to the physiopathology of TCM [2]. However, these suggestions have important limitations in convincingly explaining the pathophysiology of TCM. Multi-vessel coronary spasm and hibernating myocardium alone cannot sufficiently explain the discrepancy observed between severe apical ventricular dysfunction and slightly elevated concentrations of cardiac enzymes in some TCM patients. In addition, after the rapture of vulnerable plaque in a single coronary artery, the area of abnormal LV wall motion is not expected to extend beyond the circulation area supplied by the artery. Although ECG findings may also differ between ACS and TCM patients [35], Bybee, et al. [36] report ECG has insufficient predictive value to differentiate TCM from ACS patients. Hibernating myocardial also cannot produce histological changes seen in TCM patients [32]. Finally, inducible or spontaneous coronary artery spasm is absent in most of the observed clinical cases of TCM [10].

\section{Coronary microcirculatory disturbance}

Coronary microcirculatory disturbance has been observed as a possible pathologic mechanism of TCM. In TCM patients, abnormalities in LV wall motion occur in a large region of the apical myocardium. Since these abnormalities are dynamic, they may result into disturbances in the microvascular circulation [37]. Disturbance in coronary perfusion and severe abnormalities in myocardial metabolism in TCM patients have also been reported based on findings of thallium-201 myocardial single-photon emission computed tomography (SPECT) [29] and F-fluorodeoxyglucose myocardial positron emission tomography (PET) [28]. Elesber, et al. [38] reported microcirculatory impairment in a significant proportion of TCM patients as well as a correlation between microcirculatory disturbance and the severity of myocyte necrosis and ECG abnormalities. These studies suggest coronary microvascular impairment may contribute or accompany TCM but the association has not been sufficiently demonstrated as cause and effect. For instance, microvascular impairment may be due to elevated stress in the ventricular wall resulting from apical ballooning [10].

\section{Catecholamine toxicity}

Catecholamine toxicity of the heart has also been proposed as a possible pathophysiologic mechanism contributing to the development of TCM. Wittstein, et al. [30] compared the levels of plasma catecholamine between 13 TCM patients and seven (7) ACS patients and reported significantly higher levels of epinephrine and norepinephrine in TCM patients, suggesting the high levels of catecholamine may be the principal pathogenic feature for the development of TCM. However, Akashi, et al. [28] reported increased concentrations of plasma catecholamine are not uniform in TCM patients. Still, Frustaci, et al. [39] demonstrated that elevated levels of plasma catecholamine in TCM patients with Pheochromocytoma induces TCM. Movahed, et al. [40] supports the suggestion of catecholamine contributing to the pathophysiology of TCM by demonstrating myocardial histological changes have a striking resemblance to those in catecholamine cardiotoxicity in both animals (dogs) and human studies.

Pathophysiologic changes of TCM can be distinguishable from those of ischemic cardiac necrosis. These changes include contraction band necrosis, neutrophil-infiltration and fibrosis. The differential changes may be due to consequences of elevated intracellular concentration of calcium ions that may overload myocytes to produce ventricular dysfunction [40]. Whereas there have been reports of diffuse cardiac failure producing elevated levels of plasma catecholamine, these levels are not as high as those found on TCM patients and cannot explain catecholamine patterns in TCM patients [10]. Further, reports that plasma epinephrine levels convey a more pathological effect on cardiac function than norepinephrine suggest epinephrine induced toxicity in TCM patients. Emotional distress may also induce concomitant cardiac neuronal and adreno-medullary hormonal stimulation may occur [10]. Additionally, Lyon, et al. [41] proposed elevated plasma levels of epinephrine could trigger cardiomyocytes intracellular signaling after the occupation of beta adreno-receptors from GS protein to GI protein coupling.

\section{Neurogenic hibernating myocardium}

Neurogenic hibernating (or stunned) myocardium and ECG abnormalities in TCM patients may contribute to the pathophysiology of TCM evident by the activation of central neurogenic mechanisms mimicking those evoked by subarachnoid hemorrhage [42]. White, et al. [43] observed intracranial pathology produces similar myocardial histological and pathological outcomes observed in TCM patients. Since basal myocardium has been observed to have higher norepinephrine concentrations [44] and density of sympathetic nerves than apical myocardium [45], there are suggestions that sympathetic stimulation in the heart would not explain apical ballooning in TCM patients [10]. However, higher levels of adrenoreceptors in the LV apex may explain its pronounced myocardial responsiveness to adrenergic stimulation. [46]. Further, since cardiac sympathectomy protects against brainmediated injury in the heart, hibernating myocardium in TCM patients suggest neurogenic causes [47].

Animal studies have also indicated reduced inotropic responses to norepinephrine in the context catecholamine-induced cardiomyopathy linked with reduced levels of beta-receptors in the myocardium [48]. This finding suggests a combination of myocardial necrosis and reduced beta-adrenoreceptors responsiveness in the setting of high levels of catecholamine may contribute to the pathophysiology of TCM. Cardiac function depends on neuronal uptake to inactivate catecholamine in extra-cellular fluid [49]. Thus, increased levels of plasma catecholamine may interfere with the uptake of neuronal and increase deposition of adrenoreceptors on myocardial cells [50]. These findings support reports that emotional stress may induce cardiotoxicity due to high concentrations of circulating catecholamine.

\section{Emotional and physical stress}

Figure 3 shows the contribution of emotional stress in the pathophysiology of TCM.

Exposure to sudden and unexpected emotional stress activates neuronal cells (estrogen receptors) of the central autonomic nervous system and subsequent increase in sympathetic neuron and adrenomedullary hormonal outflows. Then adrenomedulla, and 


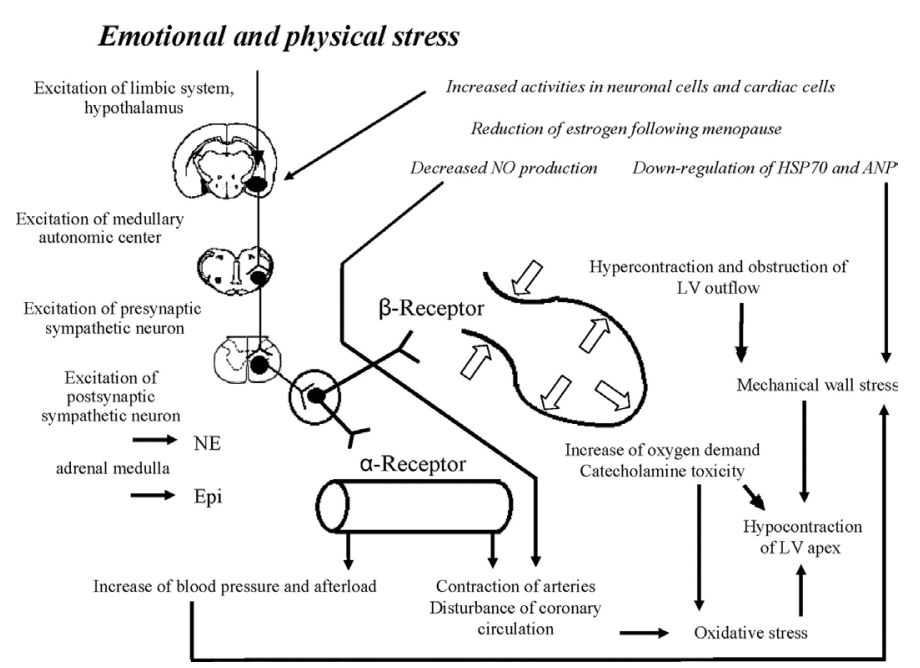

Figure 3. Pathophysiology of Emotional Stress in Takotsubo Cardiomyopathy [10]. Possible underlying mechanism for the development of Takotsubo cardiomyopathy based on adaptive and maladaptive changes following the exposure to intense physical and emotional stress.

cardiac and extra-cardiac sympathetic nerves releases epinephrine and norepinephrine reach adrenoreceptors in the blood and heart causing a rapid increase in systemic blood pressure and subsequently cardiac overload. High cardiac plasma levels of epinephrine and norepinephrine, and deposition of adrenoreceptors on cardiomyocytes induce catecholamine cardiotoxicity. Hypercontraction and functional obstruction of LV outflow together with elevated BNP levels and high end-diastolic pressure lead to an increase in mechanical wall stress in the LV apex [34]. Contraction bands and cardiomyocytes rupture occur due to a greater apical adrenoreceptors. Impaired coronary microcirculation and increased oxygen demand in cardiomyocytes alter the redox state and incudes oxidative stress leading to positive feedback loops that causes hibernation of apical myocardium. Reduced estrogen levels in postmenopausal women increases response of neuronal and cardiac cells and reduces the release of cardiomyocytes substances [10].

\section{Diagnosis}

Clinical diagnosis of TCM remains controversial because the criteria are still being developed and revised. Further, atypical types of TCM (apical, mid-ventricular, basal and focal types) complicate confirmatory diagnosis. Such atypical cases often require additional imaging techniques to visualize and exclude infarct. Localizing the area of myocardial dysfunction becomes critical to rule out the possibility of vascular involvement [51]. Moreover, the diagnosis of TCM lacks an established criterion. Expert consensus nor leading professional heart and cardiology associations are yet to provide recommendations for diagnosis. Current diagnostic criteria largely rely on two institutional research recommendations: (a) by the Mayo Clinic and (b) by the Research Committee on Idiopathic Cardiomyopathy.

\section{Diagnosis criteria}

\section{Mayo clinic}

Mayo clinic developed the first diagnostic criteria for apical ballooning syndrome (or TCM) in 2004 [19] and revised the criterion in 2014 [52]. The criteria has been widely accepted. Diagnosis is based on the presence of transient hypokinesia, akinesia, or dyskinesia of the left ventricular mid-segments with or without apical involvement; the absence of obstructive coronary disease or angiographic evidence of acute plaque rupture; and the absence of pheochromocytoma or myocarditis (Table 2).

\section{Research committee on idiopathic cardiomyopathy}

The Research Committee on Idiopathic Cardiomyopathy developed the second widely referenced diagnostic criteria for TCM (RCIC: Kwai, et al. [53]). The RCIC organized a consensus conference to develop their comprehensive diagnostic criteria for TCM based on mailed survey responses from 203 institutions between November 1989 and October 2002. The initial guidelines were prepared and evaluated in 2003, and revised and approved in 2004 [53]. The criteria are based on exlucion of other lesion and abnormalities due significant organic stenosis or spasm of coronary artery. Particular attention is acute MI caused by lesion in the anterior descending branch of left coronary artery perfusing a larger region up to the ventricular apex; cerebrovascular disease; pheochromocytoma; and viral or idiopathic myocarditis (Table 3).

The two diagnostic criteria reveal that: (a) TCM patients have nonspecific findings on physical examination; and (b) the clinical course of TCM mimics that of acute coronary syndrome or acute decompensated heart failure. However, the most frequently encountered symptoms of TCM are chest pain and dyspnea, and less frequently, patients may present with palpitations, syncope nausea, vomiting or cardiogenic shock [54-56].

\section{Multimodality imaging}

Both Mayo clinic and RCIC diagnostic criteria emphasize on the need for multimodal imaging. Different cardiac imaging modalities could be used to diagnose TCM and to investigate the underlying pathological mechanisms. They could also help in the characterization of TCM-related myocardial dysfunction and the identification of anatomical variants of TCM [57].

\section{Coronary angiography and ventriculography}

Coronary catheterization with ventriculography was the first imaging technique to identify TCM by revealing the characteristic apical ballooning (Figure 4).

The role of invasive cardiac assessment is invaluable in the differential diagnosis of TCM from acute myocardial infarction (AMI). Coronary angiography remains the mainstay imaging technique to rule out vascular origins in myocardial dysfunction in the acute stage. However, although ventriculography identifies apical ballooning and its variant forms, in the absence of ballooning, the technique provides non-confirmatory diagnosis [57].

\section{Echocardiography}

Echocardiography is an inexpensive and commonly available imaging technique effective for confirming the diagnosis of TCM.

Table 2. Diagnosis Criteria for TCM by Mayo Clinic [52].

\begin{tabular}{|l|l|}
\hline Criteria & Clinical Description \\
\hline I & $\begin{array}{l}\text { Transient hypokinesia, akinesia, or dyskinesia of the left ventricular mid- } \\
\text { segments with or without apical involvement; } \\
\text { The regional wall motion abnormalities extend beyond a single epicardial } \\
\text { vascular distribution; a stressful trigger is often, but not always present }\end{array}$ \\
\hline II & $\begin{array}{l}\text { Absence of obstructive coronary disease or angiographic evidence of acute } \\
\text { plaque rupture. }\end{array}$ \\
\hline III & $\begin{array}{l}\text { New electrocardiographic abnormalities (either ST-segment elevation and/or } \\
\text { T-wave inversion) or modest elevation in cardiac troponin }\end{array}$ \\
\hline IV & $\begin{array}{l}\text { The absence of } \\
\text { a. Pheochromocytoma } \\
\text { b. Myocarditis }\end{array}$ \\
\hline
\end{tabular}


Table 3. Diagnosis Criteria of Takotsubo Cardiomyopathy by Kwai, et al. [53]

\begin{tabular}{|c|c|}
\hline Diagnostic Criteria & Clinical Description \\
\hline I. Clinical Definition & $\begin{array}{l}\text { TCM is a cardiac condition disease characterized by acute LV apical ballooning without any demonstrable cause. The LV assumes the shape of "Takotsubo". } \\
\text { A majority of patients have a complete resolution of apical akinesia within a month. Although contraction impairment occurs mainly on the LV, in some } \\
\text { patients the RV may be involved. Dynamic LV outflow tract obstruction is also observed. Some conditions such as cerebrovascular has an apical ballooning } \\
\text { mimicking TCM but with a determinable cause and diagnosed as cerebrovascular disease with Takotsubo-like myocardial dysfunction. }\end{array}$ \\
\hline II. Exclusion Criteria & $\begin{array}{l}\text { The criteria aims to exclude lesions and abnormalities from other cardiac conditions. } \\
\text { A. Significant organic stenosis or spasm of coronary artery. Particular attention is acute MI caused by lesion in the anterior descending branch of left } \\
\text { coronary artery perfusing a larger region up to the ventricular apex. } \\
\text { B. Cerebrovascular disease } \\
\text { C. Pheochromocytoma } \\
\text { D. Viral or idiopathic myocarditis } \\
\text { Coronary angiography is required to exclude coronary artery lesions with Takotsubo-like myocardial dysfunction such as cerebrovascular disease and } \\
\text { Pheochromocytoma }\end{array}$ \\
\hline III. Diagnosis Reference & $\begin{array}{l}\text { A. Symptoms: Chest pain and dyspnea similar to that of ACS but may also occur without symptoms } \\
\text { B. Triggers: emotional/physical stress or none } \\
\text { C. Age and gender difference with known tendency to increase with age or the female gender. } \\
\text { D. Ventricular structure: apical ballooning and its rapid improvement based on ventriculogram and echocardiogram } \\
\text { E. Electrocardiogram: ST segment elevation immediately after onset. After that, T-wave becomes progressively more negative in multiple leads and QT } \\
\text { interval prolongs. These changes improve gradually but negative T-wave persists for several months. In acute stage, abnormal Q-waves and changes in } \\
\text { QRS voltage may be observed. } \\
\text { F. Cardiac biomarkers: modest elevation of serum levels of cardiac enzymes and troponin. } \\
\text { G. Myocardial radionuclear study: abnormal findings in myocardial scintigraphy in some patients } \\
\text { H. Prognosis: a majority of patients rapidly recovers but some may suffer pulmonary edema and other sequela or death. }\end{array}$ \\
\hline
\end{tabular}

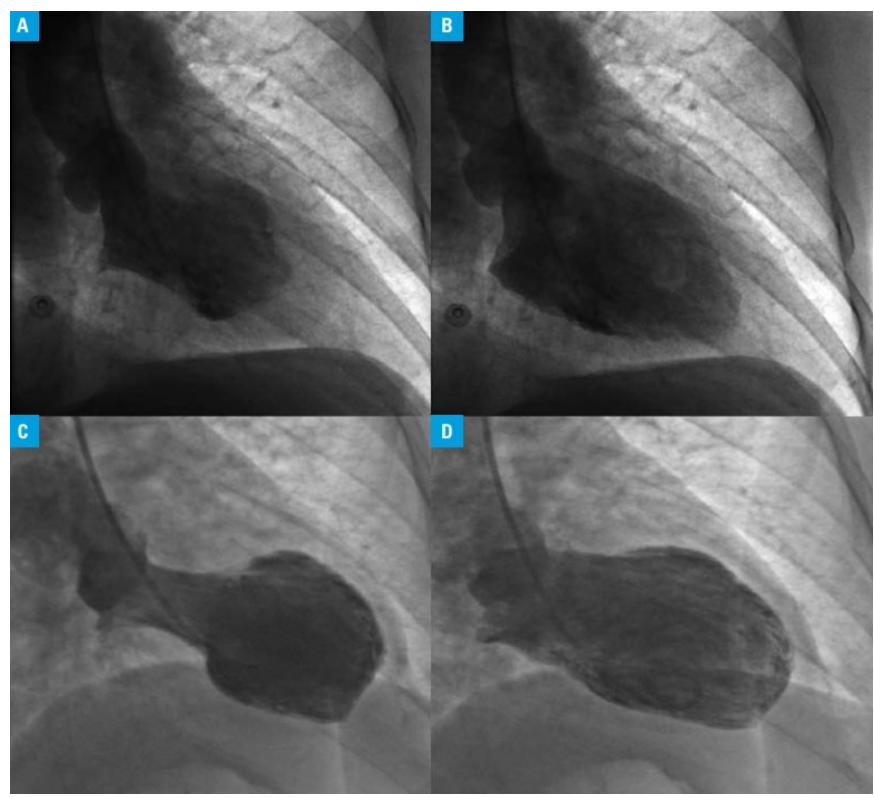

Figure 4. Left Ventriculogram Showing Apical Ballooning [58].

Freeze frames from left Ventriculogram revealing normal function at the apical and basal region during end-systole and end-diastole (A) and with akinesia of the mid segments (AB) - a mid-ventricular ballooning variant. Second Takotsubo cardiomyopathy variant with hyper-dynamic basal contraction (apical ballooning variant) at and-systole (C) and end-diastole (D).

The imaging technique can visualize apical ballooning and basal hyper-contractility as well as can detect other abnormalities related with TCM such as LV outflow tract obstruction, mitral regurgitation or the involvement of the RV wall [58,59]. Further, speckle-tracking echocardiography is able to reveal significantly impaired LV and apical function in TCM compared to AMI. This revelation has diagnostic importance in better differentiating TCM from AMI [60]. However, echocardiography may not be able to completely visualize the apex and fully characterize the extent of myocardial ballooning or akinesia [61].

\section{Cardiac magnetic resonance}

Cardiac magnetic resonance (CMR) and echocardiography are the two common imaging techniques used to visualize and characterize LV dysfunction and rule out AMI in the acute stages of TCM [59,62]. CMR compliments ventriculography and echocardiography by providing more detailed and accurate findings useful for determining the most appropriate treatment strategies [63]. Beyond the acute stages of TCM, CMR is useful in confirming diagnosis and detecting the extent of myocardial dysfunction by revealing tissue scarring [64]. Relative absence of myocardial scarring imaged using differential perfusion patterns of late gadolinium enhancement (LGE) supports the diagnosis of TCM. Furthermore, CMR can facilitate visualization of the full restoration of LV function in TCM patients by an almost complete absence of LGE in post-recovery period [65].

\section{Myocardial perfusion imaging}

Two techniques of myocardial perfusion imaging (MPI) - SPECT and PET - are commonly used in the diagnosis of TCM. SPECT uses radioactive compounds such as Thallium and I-mIBG while PET uses nitrogen-13-ammonia (NH3) or F-FDGcan for characterizing the 
degree of myocardial damage by assessing for metabolic impairment [51]. MPI are useful for diagnosis of TCM when other imaging techniques provide indeterminate findings or in the diagnosis TCM beyond the acute phase [66]. MPI has specific benefits over traditional imaging methods because it can make subtle distinction between ischemic but viable myocardium and irreversibly damaged myocardium [67] and thus is invaluable in following up patients to support diagnosis of TCM by providing additional information on myocardial recovery [66].

\section{Meta-analysis on diagnostic methods}

Diagnosis of TCM lacks a common well-defined criterion as well as diagnostic algorithm [51]. This meta-analysis reviews the key diagnostic and prognostic features of TCM with a focus on patient characteristics, signs and symptoms, and imaging findings. The aim is to advance understanding of the key clinical and echocardiographic features of TCM to improve diagnosis.

\section{Search criteria}

The search for studies assessing diagnosis and prognosis of TCM was made on online databases - PubMed, EMBASE, Ovid MEDLINE, and Google Scholar. The search terms used a combination of words/ phrases with no language restriction - transient apical ballooning syndrome, stress cardiomyopathy, Takotsubo cardiomyopathy and ampulla cardiomyopathy. Additional studies were identified from screening of bibliographies. There were no restriction on the age of the patients (studies with adults and/or children were all included). Studies having only abstracts were included if they provided sufficient information to enable data extraction. However, seminar papers were excluded because of a potential for revision (they are not considered the final paper).

\section{Inclusion criteria}

The inclusion criteria for studies was they (a) reported original data; (b) assessed more than five patients to improve statistical support for findings; (c) had at least one diagnostic method (ECG or imaging) conducted on the sampled patients. The studies also included at least one of the following diagnostic or prognostic outcomes: (a) clinical presentation; (b) patient history; (c) prognosis; (d) symptoms; (e) ECG abnormalities; (f) baseline and follow-up LVEF; (g) full recovery; (h) recovery period; and (i) documented recurrence. Studies with titles or abstracts believed to satisfy the inclusion criteria were also included for further review. However, studies including patients with cardiac conditions mimicking TCM- like LV-dysfunction or with data that is difficult to extract were excluded.

\section{Data extraction}

Each study was screened for the inclusion criteria and relevant data extracted from all the included studies. Extracted data was summarized in a Microsoft Excel Spreadsheet in two tables. The first table captured data on sample, percentage of women, emotional stressors, physiologic stressors, chest pain, dyspnea, ST-segment elevation, pathological Q waves and inverter $T$ waves. The second table captured data on baseline (at presentation) LVEF, follow-up LVEF, and percentage of patients with angiographic normal coronary artery (CA), heart failure/pulmonary edema, full recovery, recovery period and confirmed recurrence.

\section{Quality assessment}

A modified version of the Oxford Quality Scoring System (Jada scale) was utilized to assess the quality of included studies. The scoring system was useful to control bias in three key research areas: study design, recruitment/withdrawal of subjects and statistical analysis of data. Scoring was based on 11 questions. (i) Was the study described as randomized? (ii) Was there concealment of randomisation? (iii) Was there a description of withdrawals and dropouts? (iv) Were study objective defined? (v) Were outcomes measured and define clearly? (vi) Was there a clear description of inclusion and exclusion criteria? (vii) Was the patient sample justified? (viii) Was there a clear description of interventions used? (ix) Was there a control group? (x) Were methods assessing adverse effects clearly described? (xi) Were statistical methods clearly described and justified?

\section{Statistical analysis}

The primary study outcome was the incident rate of prognostic and diagnostic features of TCM to determine which features are more frequent and help to demonstrate TCM diagnosis. Data synthesis pooled together categorical and continuous data about prognostic and diagnostic features. Data analysis was descriptive, using mean, percentage and standard deviation. Weighted mean of prognostic and diagnostic features were pooled together to compare the most frequent and important features for TCM diagnosis. Qualitative analysis further identified and discussed other prognostic and diagnostic features not included in the statistical analysis but mentioned in individual studies as important in the diagnosis of TCM. Extracted data included suthor, sample, sex (women \%), emotional stressor, chest pains, dyspnea, STsegment elevation, Q-waves and inverter $\mathrm{T}$ waves (Table 4) and clinical outcomes (LEVF, heart failure/normal edema, full recovery period and confirmed recurrence (Table $4 \& 5$ ).

\section{Study characteristics}

Sixteen prospective studies or retrospective chart reviews that met the inclusion criteria were included in this meta-analysis [3-5,7-9,14$16,30,31,35,68-71]$. Tables $4 \& 5$ provide a summary of the main study characteristics. The study samples ranged from seven (7) to 88 patients. In total, 300 patients diagnosed with TCM were included in this meta-analysis. Patient characteristics (Table 4), and echocardiography abnormalities and prognostic factors (Table 5) were evaluated in all the appraised studies.

\section{Patient characteristics}

The sixteen studies revealed a marked gender discrepancy in the incident of TCM, with a disproportionately higher percentage of female involvement. Of the 300 patients included in this meta-analysis, $82 \%$ were females. Patients were generally older, with age ranging from 58 [30] to 76 years [35] (Mean $=68$ years). Fifteen studies reported emotional stress such as unexpected death of a friend or relative, domestic abuse, medical diagnosis or business losses preceded the development of TCM in $37 \%$ of the patients (range 10\% [16] to $100 \%$ [30]). Twelve (12) studies reported preceding physiological stress such as exhausting work, asthma attack and systemic disorders in $38 \%$ of the patients (range 14\% [4] to 70\% [15]). The cardinal presenting symptoms for TCM patients were chest pain and dyspnea. Sixty-eight percent $(68 \%)$ of the patients had baseline chest pain, range $20 \%$ [16] to $100 \%[68,71]$ while $38 \%$, range $5 \%$ [4] to $57 \%$ [71] presented with dyspnea.

\section{Electrocardiography findings}

The most commonly reported ECG abnormalities were ST-segment elevation and T-wave inversion occurring during the acute phase (at the time of emergency admission) and subacute phase (at 2-14 days after admission). This is consistent with Mayo Clinic [52] and RCIC 
Table 4. Summary of Patient Demographics, History, Symptoms and ECG Abnormalities.

\begin{tabular}{|c|c|c|c|c|c|c|c|c|c|c|}
\hline 1st Author [Ref. \#] & Sample & Women (\%) & Mean Age & $\begin{array}{c}\text { Emotional } \\
\text { Stressor (\%) }\end{array}$ & $\begin{array}{c}\text { Physiologic } \\
\text { Stressor (\%) }\end{array}$ & $\begin{array}{c}\text { Chest Pain } \\
(\%)\end{array}$ & Dyspnea (\%) & $\begin{array}{l}\text { ST-Segment } \\
\text { Elevation } \\
(\%)\end{array}$ & $\begin{array}{l}\text { Pathological } \\
\text { Q-Waves (\%) }\end{array}$ & $\begin{array}{c}\text { Inverted } \\
\text { T-Waves (\%) }\end{array}$ \\
\hline Bybee, et al. [3] & 16 & 69 & 71 & 38 & 44 & 69 & 25 & 81 & 31 & 81 \\
\hline Sharkey, et al. [4] & 22 & 91 & 65 & 86 & 14 & 91 & 5 & 59 & 45 & 68 \\
\hline Kawai, et al. [5] & 9 & 100 & 66 & 22 & 33 & 33 & 53 & 100 & NR & NR \\
\hline Kurisu, et al. [7] & 30 & 93 & 70 & 17 & 17 & 63 & 20 & 100 & NR & 43 \\
\hline Ito, et al. [8] & 7 & 71 & 65 & 57 & NR & 71 & 43 & 100 & NR & NR \\
\hline Desmet, et al. [9] & 13 & 92 & 62 & 23 & 46 & 62 & 31 & 62 & 31 & 92 \\
\hline Ito, et al. [14] & 10 & 70 & 63 & 30 & 40 & 80 & 40 & 100 & NR & 100 \\
\hline Matsuoka, et al. [15] & 10 & 90 & 68 & 30 & 70 & 60 & 30 & 100 & NR & NR \\
\hline Akashi, et al. [16] & 10 & 90 & 73 & 10 & 50 & 20 & 20 & 90 & 100 & 100 \\
\hline Wittstein, et al. [30] & 19 & 95 & 58 & 100 & NR & 95 & NR & 11 & 38 & 95 \\
\hline Tsuchihashi, et al. [31] & 88 & 86 & 67 & 20 & 45 & 67 & 7 & 90 & 27 & 44 \\
\hline Inoue, et al. [35] & 18 & 61 & 76 & 11 & 39 & 61 & NR & NR & NR & NR \\
\hline Ibanez, et al. [68] & 11 & 82 & 72 & 27 & 27 & 100 & NR & 100 & NR & 82 \\
\hline Ogura, et al. [69] & 13 & 69 & 75 & NR & NR & NR & NR & NR & 15 & 31 \\
\hline Abe, et al. [70]. & 17 & 82 & 74 & 18 & 35 & 53 & 29 & 82 & 15 & 31 \\
\hline Sugihara, et al. [71] & 7 & 71 & NR & 71 & NR & 100 & 57 & 100 & NR & NR \\
\hline Total/Average & 300 & 82 & 68 & 37 & 38 & 68 & 30 & 84 & 38 & 70 \\
\hline
\end{tabular}

Table 5. Summary of LV Function and Imaging Findings and Prognostication

\begin{tabular}{|c|c|c|c|c|c|c|c|}
\hline 1st Author [Ref. \#] & Baseline LVEF (\%) & $\begin{array}{c}\text { Follow-up LVEF } \\
(\%)\end{array}$ & $\begin{array}{c}\text { Angiography } \\
\text { Normal CA (\%) }\end{array}$ & $\begin{array}{c}\text { Heart Failure/ } \\
\text { Pulmonary Edema } \\
(\%)\end{array}$ & Full Recovery (\%) & $\begin{array}{c}\text { Recovery Period } \\
\text { (Days) }\end{array}$ & $\begin{array}{c}\text { Confirmed } \\
\text { Recurrence (\%) }\end{array}$ \\
\hline Bybee et al. [3] & 39 & 60 & 25 & 44 & 100 & 8 & 6 \\
\hline Sharkey et al. [4] & 29 & 63 & NR & 0 & 100 & 24 & 9 \\
\hline Kawai et al. [5] & NR & 76 & 100 & NR & 100 & 22 & NR \\
\hline Kurisu et al. [7] & 49 & 69 & 83 & 3 & 100 & 11 & NR \\
\hline Ito et al. [8] & NR & NR & 100 & 0 & NR & NR & NR \\
\hline Desmet et al. [9] & NR & NR & 38 & 50 & 92 & 27 & 15 \\
\hline Ito et al. [14] & 44 & 72 & NR & NR & 100 & NR & NR \\
\hline Matsuoka et al. [15] & 48 & 72 & 100 & NR & 100 & 16 & NR \\
\hline Akashi et al. [16] & 42 & 64 & 100 & 0 & 100 & 18 & 0 \\
\hline Wittstein et al. [30] & 20 & 60 & 95 & 16 & 100 & NR & 0 \\
\hline Tsuchihashi et al. [31] & 41 & 64 & NR & 23 & 97 & NR & 2.7 \\
\hline Inoue et al. [35] & NR & NR & NR & 5.6 & NR & NR & NR \\
\hline Ibanez et al. [68] & 37 & 64 & 100 & NR & 100 & 13 & NR \\
\hline Ogura et al. [69] & NR & NR & 100 & NR & 100 & NR & NR \\
\hline Abe et al. [70]. & NR & NR & 100 & NR & NR & 30 & 0 \\
\hline Sugihara et al. [71] & 44 & 72 & 100 & NR & NR & NR & NR \\
\hline Total/Average & 39 & 67 & 87 & 16 & 99 & 19 & 5 \\
\hline
\end{tabular}

LVEF: Left Ventricular Ejection Fraction; CA: Coronary Artery

[53] diagnostic criteria, suggesting ST-segment elevation, pathological Q-wave and T-wave inversion are common ECG abnormalities in TCM patients. ST-segment elevation was reported in 14 studies totaling $84 \%$ of the patients (range: $11 \%$ [30] to $100 \%$ [5,7,8,14,15,68,71]. Eight studies $[3,4,9,16,30,31,69,70]$ reported $84 \%$ of TCM patients included in this meta-analysis presented with pathological Q-waves. Eleven (11) studies reported inverted $\mathrm{T}$-waves in $70 \%$ of the patients with range $31 \%[69,70]$ to $100 \%[14,16]$.

\section{Catheterization and echocardiography findings}

All the 16 studies assessed coronary stenosis using angiography to determine significant CAD. However, four studies did not report additional details. In the remaining twelve studies, the majority of patients (87\%) had normal coronary arteries (100\%) [5,8,15,16,6871] while the remaining four studies reported mean luminal stenosis of $95 \%$ [30], $83 \%$ [7], 38\% [9], and 25\% [3]. Ten studies [3,4,7,14$16,30,31,68,71]$ reported baseline LVEF (Mean $=39 \%$; Range $=20 \%$
[30] to $49 \%$ [7]) while 11 studies [3-5,7,14-16,30,31,68,71] reported follow-up LEVF (Mean $=67 \%$; Range $=60 \%[3,30]$ to $76 \%[5]$ ). The findings show significant improvement in mean LVEF from 39\% at admission (acute phase) and 67\% at follow-up (days to weeks: sub-acute phase) suggesting the transiency of TCM-associated LV dysfunction as assessed by either or both echocardiography or ventriculography. Midventricular and apical wall abnormalities resolved in all the surviving patients.

\section{Prognosis}

The reviewed studies report favorable prognosis of TCM. The most frequently reported clinical complication by nine (9) studies [3,4,7$9,16,30,31,35]$ was heart failure with or without pulmonary edema in $16 \%$ of the patients. Twelve studies [3-7,9,14-16,30,31,68,69] reported full recovery of LV function in $99 \%$ of the patients within a mean period of 19 days, range 8 [3] to 30 days [70]). Only seven studies documented recurrence of $\mathrm{LV}$ dysfunction in 5\% (range 2.7\% [31] to 15\% [9]) of 
the recruited TCM patients. However, the true prevalence of TCM recurrence is limited since most studies did not evaluate all patients at follow-up and follow-up time varied significantly among the studies.

\section{Discussion}

The lack of large-scale clinical trials or population-based studies on TCM has continued to undermine a precise understanding of its pathophysiology, prognosis and diagnosis. However, for the past two decades, several case series have suggested it is a distinct form of cardiomyopathy but which has lacked proper clinical recognition as well as a clear prognostic description and diagnostic guidelines. The case series have identified several clinical features of TCM useful for its clinical diagnosis. The present meta-analysis reveals that TCM has a statistically significant gender bias towards women, who account for up to $82 \%$ of the total TCM patients included in this meta-analysis. In addition, women diagnosed with TCM were much older, in the age range of 58 to 76 years $[30,35]$. These present findings are consistent with findings of case series reports, which have implicated the female gender as a significant risk factor for developing TCM [19-21], accounting for between $80 \%$ [29] and $100 \%$ [3] of TCM patients. Older women (in post-menstrual age brackets) have the highest risk of developing TCM $[19,20]$. This cohort has reduced levels of estrogen, which is an important factor for the development of TCM [20]. Estrogen protects against the development of TCM by playing a role in the inhibition of cardiotoxicity caused by catecholamine toxicity, calcium overload and reduced oxidative stress, which collectively are key factors underlying the development of TCM [22]. Furthermore, estrogen therapy has also been associated with significant reduction in the incident of TCM in post-menstrual women [19], demonstrating its cardioprotective effect against the development of TCM.

This meta-analysis also finds emotional (37\%) and physiological stress (38\%) are key factors associated with TCM. Principal sources of emotional stress are death of a close family member or friend, medical diagnosis or loss of job while sources of physiological stress are exhausting work, systemic disorders or exhausting work. These findings suggests the presence of emotional or physiological stress is an important supporting diagnostic feature for TCM. The association between stress and the development of TCM has been reported in several earlier studies. More specifically, emotional and physiological stress following devastation by natural disasters have been associated with significantly increased incidents of TCM $[18,19]$. According to Akashi and associates [10], emotional stress stimulates estrogen receptors in the central nervous system causing an increase in sympathetic neuron and adrenomedullary secretion of epinephrine and norepinephrine hormones leading to cardiac overload and catecholamine cardiotoxicity. Further, depressed estrogen levels reduces cardiac ability to secrete cardiomyocytes substances that provide cardio-protection against catecholamine cardiotoxicity [10]. In addition to stress, the most frequent clinical symptoms are chest pains, present in $68 \%$ of TCM patients $[16,68,71]$ and dyspnea present in $38 \%$ of TCM patients $[4,71]$. The prevalence of chest pains and dyspnea in TCM patients has been reported in several case series $[3,4,7,12,18,31]$. These case series report the incident rate of chest pains ranging between 54\% [28] and $100 \%$ [18]. Chest pains in TCM patients mimics that of acute myocardial infarction, which complicates diagnosis. It is important that TCM diagnosis should include the exclusion of acute myocardial infarction.

The two most frequent clinical features supporting clinical diagnosis of TCM in the present meta-analysis are electrocardiographic (ECG) abnormalities and angiographic defined coronary artery.
ECG abnormalities - ST-segment elevation and T-wave inversion were reported in $84 \%$ and $74 \%$ of TCM patients respectively while echocardiographic luminal stenosis and LVEF (mean $<39 \%$ ) were the most common diagnostic clues. Changes in LVEF between baseline (39\%) and follow-up (67\%) indicates TCM is a transient myocardial condition. The importance of ECG abnormalities and angiographicdefined coronary artery in the diagnosis of TCM have been supported by the two current proposed diagnostic criteria - by Mayo Clinic and by RCIC. The two criteria agree that ST-segment elevation, pathological Q-wave and T-wave inversion are common ECG abnormalities in TCM patients. The two criteria also recommend the exclusion of obstructive coronary disease for the diagnosis of TCM. Case series also show that ST-segment elevation and Q-waves are common in TCM patients $[3,7,28,31]$. These case series also report significant improvement in LVEF function suggesting transiency of TCM.

In summary, the reviewed studies demonstrate that TCM has a marked gender discrepancy significantly affecting more postmenopausal women than men. Emotional or physiological stress emerges as an important preceding factor in the development of TCM in a majority of patients while chest pain and dyspnea are the most commonly encountered presenting symptoms. ECG abnormalities (ST-segment elevation, pathological Q-eaves and inverter T-waves) are common diagnostic features. Echocardiography or ventriculography are important diagnostic and prognostic techniques for assessing LV dysfunction (LVEF) and reveals marked improvement in LV function between acute and sub-acute phases. Finally, prognosis is favorable with fewer reported complications (heart failure with or without pulmonary edema) and full recovery within days to weeks.

\section{Clinical management}

Unlike other forms of cardiomyopathies, TCM has no established treatment guidelines and its management is based on empirical research findings. Further, the lack of randomized trials or medical guidelines to establish treatment, the current clinical management lacks fully defined measures and there is no consensus among experts [72]. However, clinical management approaches have been divided into two: one for acute phase and the other for chronic phase of TCM.

\section{Acute phase \\ Pharmacotherapy}

The acute phase of TCM requires standard supportive therapy [72] Initial clinical management usually targets treating myocardial ischemia (MI). Standard treatment consists of administration of antiplatelet duotherapy: Aspirin, Clopidogrel, heparin, beta-blocker or angiotensin converting enzyme (ACE)-inhibitor because the acute phase of TCM is difficult to distinguish definitively from acute coronary syndromes (ACS). Antiplatelet duo-therapy is usually withdrawn if acute MI has been excluded but may be maintained if coronary atherosclerosis has been demonstrated because of increased risk of plaque rapture or hemorrhaging $[73,74]$. Although vasoactive drugs or inotropes may provide pharmacological support, some studies suggest mechanical circulatory support because of the involvement of catecholamine $[75,76]$. Early administration of calcium channel blockers has also been shown to improve the restoration of LV systolic function but its chronic use may not achieve the same clinical outcome [77,78]. However, the administration of calcium channel blockers should be individualized because of different management plans mostly for patients with dynamic intraventricular pressure gradients with hypotension in the setting of depressed LV function [72]. 


\section{Intra-aortic balloon pump counterpulsation}

Since accumulation of catecholamine is believed to be critical to the pathogenesis of TCM, intra-aortic balloon counterpulsation (IABC) may be introduced early instead of the administration of inotropes. Further, IABC provides life-sustaining mechanical circulatory support for TCM patients experiencing cardiogenic shock [72]. Alternatives to IABC include intra-aortic balloon pump (IABP) [76] or extracorporeal life support [79]. Short-term anticoagulation therapy may be considered until full restoration of ventricular function. If tolerated, intravenous heparin may be administered to prevent LV apical thrombosis and continued with warfarin until full restoration of ventricular function [73].

\section{Chronic phase}

\section{Pharmacologic support}

In the chronic phase of TCM, there is complete restoration of ventricular function and patients have a favorable prognosis. In these patients, chronic anxiolytic therapy could be considered to protect against recurrence and to treat physical stressors that could trigger recurrence [73,74]. ACE-inhibitor or Angiotensin Receptor Blockers (ARB) may also be used to reduce the risk of recurrence and improve survival better than the administration of beta-blockers $[80,81]$. Although pharmacotherapy could reduce the risk of recurrence, there is no supportive evidence on the use of chronic pharmacotherapy except in cases of cardiac dysfunction [72]. Further, a meta-analysis study on chronic pharmacotherapy to prevent TCM recurrence indicates no clinically beneficial protective effect [82].

\section{Hormonal supplementation therapy}

The benefits of estradiol are a still under experiment and evaluation in the management of chronic phase of TCM. Experimental animal studies have demonstrated significant reduction of stress-induced LV dysfunction and arrhythmias suggesting its value in clinical management of TCM after echocardiography-established complete recovery of the LV function. Estrogen has also been well demonstrated to have cardioprotective effect against myocardial damage in the context of ischemia or reperfusion. However, the pathogenesis of TCM cannot be explained in the absence of estrogen since men rarely develop TCM $[83,84]$.

\section{Meta-analysis of TCM clinical management}

Clinical management of TCM is not well established. Although mechanical circulatory support is recommended in the acute phase of TCM, and hormonal supplementation therapy as a prophylactic management approach, pharmacotherapy remains the most frequently used clinical management approach in both acute and chronic phase of TCM. This meta-analysis aims to investigate the clinical value of pharmacotherapy in the treatment of TCM.

\section{Search criteria}

Studies for inclusion in this meta-analysis were searched on PubMed, EMBASE, Ovid MEDLINE, and Google Scholar. A combination of wide search terms were used to find as many as possible published studies on clinical management of TCM. The search terms were apical ballooning syndrome, Takotsubo, stress, or ampulla cardiomyopathy. Additional study titles gleaned from the perusal of reference list and library were also included for detailed analysis prior to appraisal. Case reports with one to three patients were excluded because of statistical inadequacy to support findings beyond the study population. A hierarchical approach (title, abstract and manuscript) was utilized to screen all the retrieved citations for inclusion.

\section{Inclusion criteria}

Studies were included if they (a) recorded primary data; (b) assessed pharmacologic therapy; (c) included at least one of the following clinical outcomes: (a) recurrent chest pain; (b) re-hospitalization for cardiac reasons; (c) TCM recurrence; and (d) in-hospital mortality. Titles and/or abstract of studies were perused and those suspected to meet the inclusion criteria were included for detailed analysis. There was no restriction on publication language or age of the patients. Studies recruiting either or both pediatric and/or adult patients were eligible for inclusion.

\section{Statistical analysis}

The primary study outcome was clinical indication of disease progression: symptoms (chest pain) recurrence, disease recurrence, re-hospitalization and mortality. Data synthesis pooled together categorical and continuous data about TCM symptoms and recurrence. Data analysis for categorical data was descriptive, using mean, percentage and standard deviation. Weighted mean of symptoms and disease recurrence were pooled together to compare the clinical efficacy of pharmacotherapy on treatment of TCM. Qualitative analysis further identified and discussed other TCM management approaches not included in the quantitative analysis. The extracted data were study period, sample size, sex, mean, medial follow-up, ruccerenct chest pain, rehiospitalization and TCM recurrende and mortalit (Table 6)

\section{Study/Patient characteristics}

Ten prospective or retrospective studies [58,85-93] examining pharmacologic support for TCM patients that met the inclusion criteria were included in this meta-analysis. The study period ranged from 1998 $[86,87]$ to $2010[87,88,92]$. The ten studies included a total sample of 551 TCM patients with a vast majority $(96 \%)$ begin postmenopausal women, mean age 69 years ranging from a mean of 64 years [87] to 73 years $[89,90]$. The main medication used were beta-blockers, Angiotensin-Converting Enzyme (ACE) inhibitors/ Angiotensin Receptor Blockers (ARB), aspirin and statins.

\section{Clinical outcomes}

Findings from the ten appraised studies indicate chronic pharmacologic therapy for TCM in a mean follow up period of 3.7 years (range $=2.00$ [90] to 8.3 [87] years) has high recurrence of chest pains reported in $24.7 \%$ of the patients (range $=4.7 \%$ [89] to $78 \%$ [88]). Re-hospitalization for cardiac reasons was also high affecting $17.9 \%$ of the TCM patients on pharmacologic therapy. TCM recurrence within a mean period of 3.7 years was reported in $4.3 \%$ of the patients suggesting medication is less efficacious in the prevention of TCM recurrence. Mortality rate was also high at a mean of $6.2 \%$ of the total number of patients.

\section{Discussion}

Although TCM lacks well-established clinical management guidelines, its treatment has been largely pharmacologic. This metaanalysis finds the standard medical treatment of TCM includes antiplatelet duo-therapy of Aspirin and Clopidogrel, and heart failure medication such as beta-blocker and/or angiotensin converting enzyme (ACE)-inhibitor/Angiotensin Receptor Blockers (ARB) [73,74]. The value of pharmacotherapy has been already established. Antiplatelet duo-therapy is usually recommended if coronary atherosclerosis has 
Table 6. Studies on Pharmacologic Management of TCM

\begin{tabular}{|c|c|c|c|c|c|c|c|c|c|}
\hline 1st Author [Ref. \#] & Study Period & Sample Size & Female (\%) & Mean Age & $\begin{array}{c}\text { Median Follow- } \\
\text { up (Years) }\end{array}$ & $\begin{array}{l}\text { Recurrent } \\
\text { Chest Pain }\end{array}$ & \begin{tabular}{|c|} 
Re- \\
Hospitalization \\
for cardiac \\
reasons (\%)
\end{tabular} & $\begin{array}{c}\text { TCM } \\
\text { Recurrence }\end{array}$ & Mortality (\%) \\
\hline Opolski, et al. [58] & $2005-2010$ & 31 & 94 & 67 & 2.60 & 6.5 & 6.5 & 0.0 & 3.2 \\
\hline Ionescu, et al. [85] & $2003-2008$ & 27 & 96 & 68 & 2.25 & 7.4 & 29.6 & 7.4 & 14.8 \\
\hline Elesber, et al. [86] & $1998-2005$ & 100 & 95 & 66 & 4.70 & 31.0 & 12.0 & 10.0 & 17.0 \\
\hline Khalighi, et al. [87] & $1998-2010$ & 12 & 100 & 64 & 8.30 & 33.0 & 8.3 & 0.0 & 0.0 \\
\hline Looi, et al. [88] & $2004-2010$ & 100 & 95 & 65 & 3.00 & 78.0 & 26.0 & 7.0 & 4.0 \\
\hline Kurisu, et al. [89] & $2008^{*}$ & 21 & 95 & 73 & 3.00 & 4.7 & NR & NR & 5.0 \\
\hline Parodi, et al. [90] & $2003-2008$ & 116 & 91 & 73 & 2.00 & 12.0 & 25.0 & 1.7 & 9.0 \\
\hline Samardhi, et al. [91] & $2012 *$ & 52 & 98 & 71 & 3.5 & NR & NR & 0.0 & 0.0 \\
\hline Cacciotti, et al. [92] & 2004-2010 & 75 & 97 & 72 & 2.2 & NR & NR & 1.3 & 2.6 \\
\hline Brenner, et al. [93] & 2003-2005 & 17 & 100 & 67 & 5.0 & NR & NR & 11.0 & NR \\
\hline Total/Average & & 551 & 96 & 69 & 3.7 & 24.7 & 17.9 & 4.3 & 6.2 \\
\hline
\end{tabular}

*Study period not indicated

been demonstrated alongside TCM. Beta-blockers and ACE-inhibitors/ $\mathrm{ARB}$ are recommended to ease TCM symptoms, since distinguishing TCM from acute myocardial infarction is always challenging. Pharmacotherapy has also been shown to prevent TCM recurrence and treat stressors that may trigger recurrence [74]. In addition to heart failure medication, chronic anxiolytic therapy is recommended to treat stressors and reduce the likelihood of TCM recurrence. Hormonal supplementation therapy may prove beneficial in elevating the levels of estrogen and prevent the development of TCM. However, its use is still experimental in animal studies, which have demonstrated a cardioprotective effect against myocardial damage and improvement in LVEF function $[83,84]$.

Although pharmacotherapy has protective value against TCM symptoms and recurrence $[80,81]$, the present meta-analysis reveals it is less efficacious in preventing TCM recurrence in the long-term. About a quarter of TCM patients (24.7\%) had a recurrence of TCM symptoms (chest pains), re-hospitalization (17.9\%) and TCM recurrence $(4.3 \%)$ within a mean of 3.7 years. According to Rivera [72], pharmacotherapy may be effective in the short-term but in the long-term its efficacy is not clearly known. Currently, there is a lack of studies investigating the value of chronic pharmacotherapy to TCM patients in the prevention of symptoms, recurrence, hospitalization or mortality. However, chronic medication has been shown to be effective in TCM patients with demonstrable cardiac dysfunction but its effect on protecting against recurrence or disease progression has limited or no clinical value [82].

In summary, although pharmacotherapy is frequently used in the management of TCM its clinical efficacy in the long-term suggests it is less efficacious. Standard medication - beta-blockers, ACE-inhibitors/ $\mathrm{ARB}$, aspirin and statins do not seem to protect against recurrence of symptoms (chest pain), TCM and re-hospitalization all demonstrate that pharmacotherapy in the long-term has limited protective effect against the development or recurrence of TCM. There is need for additional studies on the value of chronic medication for the prevention of TCM recurrence or a duo therapy with chronic anxiolytic medication in the prevention of stressors and subsequent TCM recurrence.

\section{Conclusion}

Takotsubo cardiomyopathy (TCM) is a recently described myocardial condition characterized by transient and easily reversible contractile dysfunction usually involving the LV apex and midventricular segments with electrocardiographic (ECG) abnormalities mimicking acute myocardial infarction (AMI). TCM is clinically categorized into apical, mid-ventricular, basal or focal TCM based on the location of the left ventricular wall motion. The cardiac condition has a clear gender bias with women accounting for over $80 \%$ of the patients. The main risk factors for developing TCM are depressed estrogen hormonal levels (explaining the high prevalence in postmenstrual women), exposure to intense emotional or physiologic stress, and genetic factors. Chest pains and dyspnea are the predominant clinical symptoms. Prognosis of TCM is favorable because of it is transient and easily reversible. The main pathophysiologic mechanisms are multivessel epicardial coronary artery spasm, coronary microcirculation disturbance, catecholamine cardiotoxicity, hibernating myocardium and exposure to emotional/physiologic stress. While diagnosis is not well established, Mayo Clinic and the Research Committee on Idiopathic Cardiomyopathy proposed diagnostic criteria based on ECG abnormalities (ST-segment elevation, inverted T-waves and pathologic Q-waves) and angiographic-evidence of coronary artery stenosis. Clinical management includes pharmacotherapy, anxiolytic therapy, circulatory support, and hormonal supplementation therapy (although still under experimentation). Despite pharmacologic support, TCM has an a high rate of recurrence in the long-term.

\section{References}

1. Iga K, Gen H, Tomonaga G, Matsumura T, Hori K (1989) Reversible left ventricular wall motion impairment caused by pheochromocytoma--a case report. Jpn Circ J 53: 813-818. [Crossref]

2. Sato H, Tateishi H, Uchida T (1990) Takotsubo-type cardiomyopathy due to multivessel spasm. In Kodama, K., Haze, K., Hon, M. (Eds). Clinical Aspect of Myocardial Injury: From Ischemia to Heart Failure. Tokyo, Japan: Kagakuhyouronsha, 56-64.

3. Bybee KA, Prasad A, Barsness GW, Lerman A, Jaffe AS, et al. (2004) Clinical characteristics and thrombolysis in myocardial infarction frame counts in women with transient left ventricular apical ballooning syndrome. Am J Cardiol 94: 343-346. [Crossref]

4. Sharkey SW, Lesser JR, Zenovich AG, Maron MS, Lindberg J, et al. (2005) Acute and reversible cardiomyopathy provoked by stress in women from the United States. Circulation 111: 472-479. [Crossref]

5. Kawai S, Suzuki H, Yamaguchi H, Tanaka K, Sawada H, et al. (2000) Ampulla cardiomyopathy ('Takotusbo' cardiomyopathy) - Reversible left ventricular dysfunction: with ST segment elevation. Jpn Circ J 64: 156-159. [Crossref]

6. Dote K, Sato H, Tateishi H, Uchida T, Ishihara M (1991) Myocardial stunning due to simultaneous multi-vessel coronary spasms: A review of 5 cases. J Cardiol 21: 203214. [Crossref]

7. Kurisu S, Sato H, Kawagoe T, Ishihara M, Shimatani Y, et al. (2002) Tako-tsubo-like left ventricular dysfunction with ST-segment elevation: A novel cardiac syndrome mimicking acute myocardial infarction. Am Heart J 143: 448-455. [Crossref] 
8. Ito K, Sugihara H, Kawasaki T, Yuba T, Doue T, et al. (2001) Assessment of ampulla (Takotsubo) cardiomyopathy with coronary angiography, two-dimensional echocardiography and $99 \mathrm{mTc}$-tetrofosmin myocardial single photon emission computed tomography. Ann Nucl Med 15: 351-355. [Crossref]

9. Desmet WJ, Adriaenssens BF, Dens JA (2003) Apical ballooning of the left ventricle: first series in white patients. Heart 89: 1027-1031. [Crossref]

10. Akashi YJ, Goldstein DS, Barbaro G, Ueyama T (2008) Takotsubo cardiomyopathy: a new form of acute, reversible heart failure. Circulation 118: 2754-2762. [Crossref]

11. Templin C, Ghadri JR, Diekmann J, Napp LC, Bataiosu DR, et al. (2015) Clinical Features and Outcomes of Takotsubo (Stress) Cardiomyopathy. N Engl J Med 373: 929-938. [Crossref]

12. Kurowski V, Kaiser A, von Hof K, Killermann DP, Mayer B, et al. (2007) Apical and midventricular transient left ventricular dysfunction syndrome (tako-tsubo cardiomyopathy): Frequency, mechanisms, and prognosis. Chest 132: 809-816. [Crossref]

13. Gianni M, Dentali F, Grandi AM, Sumner G, Hiralal R, et al. (2006) Apical ballooning syndrome or takotsubo cardiomyopathy: A systematic review. Eur Heart J 27: 15231529. [Crossref]

14. Ito K, Sugihara H, Katoh S, Azuma A, Nakagawa M (2003) Assessment of Takotsubo (ampulla) cardiomyopathy using $99 \mathrm{mTc}$-tetrofosmin myocardial SPECT-comparison with acute coronary syndrome. Ann Nucl Med 17: 115-122. [Crossref]

15. Matsuoka K, Okubo S, Fujii E, Uchida F, Kasai A, et al. (2003) Evaluation of the arrhythmogenicity of stress-induced 'takotsubo cardiomyopathy' from the time course of the 12-lead surface electrocardiogram. Am J Cardiol 92: 230-233.

16. Akashi YJ, Nakazawa K, Sakakibara M, Miyake F, Musha H, et al. (2004) 123I-MIBG myocardial scintigraphy in patients with 'takotsubo' cardiomyopathy. J Nucl Med 45: 1121-1127. [Crossref]

17. El-Sayed AM, Brinjikji W, Salka S (2012) Demographic and co-morbid predictors of stress (takotsubo) cardiomyopathy. Am J Cardiol 110: 1368-1372. [Crossref]

18. Sato M, Fujita S, Saito A, Ikeda Y, Kitazawa H, et al. (2006) Increased incidence of transient left ventricular apical ballooning (socalled "Takotsubo" cardiomyopathy) after the mid-Niigata Prefecture earthquake. Circ J 70: 947-953. [Crossref]

19. Komamura K, Fukui M, Iwasaku T, Hirotani S, Masuyama T (2014) Takotsubo cardiomyopathy: pathophysiology, diagnosis and treatment. World J Cardiol 6: 602609. [Crossref]

20. Kuo BT, Choubey R, Novaro GM (2010) Reduced estrogen in menopause may predispose women to takotsubo cardiomyopathy. Gend Med 7: 71-77. [Crossref]

21. Ueyama T, Hano T, Kasamatsu K, Yamamoto K, Tsuruo Y, et al. (2003) Estrogen attenuates the emotional stress-induced cardiac responses in the animal model of takotsubo (Ampulla) cardiomyopathy. J Cardiovasc Pharmacol 42: S117-S120. [Crossref]

22. Migliore F, Bilato C, Isabella G, Iliceto S, Tarantini G (2010) Haemodynamic effects of acute intravenous metoprolol in apical ballooning syndrome with dynamic left ventricular outflow tract obstruction. Eur J Heart Fail 12: 305-308. [Crossref]

23. Abraham J, Mudd JO, Kapur NK, Klein K, Champion HC, et al. (2009) Stress cardiomyopathy after intravenous administration of catecholamines and beta-receptor agonists. J Am Coll Cardiol 53: 1320-1325. [Crossref]

24. Cevik C, Nugent K (2008) The role of cardiac autonomic control in the pathogenesis of tako-tsubo cardiomyopathy. Am Heart $J$ 156: e31. [Crossref]

25. Barton DA, Dawood T, Lambert EA, Esler MD, Haikerwal D, et al. (2007) Sympathetic activity in major depressive disorder: identifying those at increased cardiac risk? $J$ Hypertens 25: 2117-2124. [Crossref]

26. Zaroff JG, Pawlikowska L, Miss JC, Yarlagadda S, Ha C, et al. (2006) Adrenoceptor polymorphisms and the risk of cardiac injury and dysfunction after subarachnoid hemorrhage. Stroke 37: 1680-1685. [Crossref]

27. Spinelli L, Trimarco V, Di Marino S, Marino M, Iaccarino G, et al. (2010) L41Q polymorphism of the $\mathrm{G}$ protein coupled receptor kinase 5 is associated with left ventricular apical ballooning syndrome. Eur J Heart Fail 12: 13-16. [Crossref]

28. Akashi YJ, Musha H, Kida K, Itoh K, Inoue K, et al. (2005) Reversible ventricular dysfunction takotsubo cardiomyopathy. Eur J Heart Fail 7: 1171-1176. [Crossref]

29. Yoshida T, Hibino T, Kako N, Murai S, Oguri M, et al. (2007) A pathophysiologic study of tako-tsubo cardiomyopathy with F-18 fluorodeoxyglucose positron emission tomography. Eur Heart J 28: 2598-2604. [Crossref]
30. Wittstein IS, Thiemann DR, Lima JA, Baughman KL, Schulman SP, et al. (2005) Neurohumoral features of myocardial stunning due to sudden emotional stress. $N$ Engl J Med 352: 539-548. [Crossref]

31. Tsuchihashi K, Ueshima K, Uchida T, Oh-mura N, Kimura K, et al. (2001) Transient left ventricular apical ballooning without coronary artery stenosis: A novel heart syndrome mimicking acute myocardial infarction: Angina Pectoris-Myocardial Infarction Investigations in Japan. J Am Coll Cardiol 38: 1-18. [Crossref]

32. Nef HM, Möllmann H, Weber M, Deetjen A, Brandt R, et al. (2007) Release pattern of cardiac biomarkers in left ventricular apical ballooning. Int J Cardiol 115: 128-129. [Crossref]

33. Akashi YJ, Musha H, Nakazawa K, Miyake F (2004) Plasma brain natriuretic peptide in takotsubo cardiomyopathy. QJM 97: 599-607. [Crossref]

34. Akashi YJ, Tejima T, Sakurada H, Matsuda H, Suzuki K, et al. (2004) Left ventricular rupture associated with Takotsubo cardiomyopathy. Mayo Clin Proc 79: 821-824. [Crossref]

35. Inoue M, Shimizu M, Ino H, Yamaguchi M, Terai H, et al. (2005) Differentiation between patients with takotsubo cardiomyopathy and those with anterior acute myocardial infarction. Circ J 69: 89-94. [Crossref]

36. Bybee KA, Motiei A, Syed IS, Kara T, Prasad A, et al. (2007) Electrocardiography cannot reliably differentiate transient left ventricular apical ballooning syndrome from anterior ST-segment elevation myocardial infarction. J Electrocardiol 40: 38.e1-38. e6. [Crossref]

37. Kume T, Akasaka T, Kawamoto T, Yoshitani H, Watanabe N, et al. (2005) Assessment of coronary microcirculation in patients with takotsubo-like left ventricular dysfunction. Circ J 69: 934-939. [Crossref]

38. Elesber A, Lerman A, Bybee KA, Murphy JG, Barsness G, et al. (2006) Myocardial perfusion in apical ballooning syndrome correlate of myocardial injury. Am Heart $J$ 152: 469.e9-469.e13. [Crossref]

39. Frustaci A, Loperfido F, Gentiloni N, Caldarulo M, Morgante E, et al. (1991) Catecholamine-induced cardiomyopathy in multiple endocrine neoplasia: a histologic, ultrastructural, and biochemical study. Chest 99: 382-385. [Crossref]

40. Movahed A, Reeves WC, Mehta PM, Gilliland MG, Mozingo SL, et al. (1994) Norepinephrine-induced left ventricular dysfunction in anesthetized and conscious, sedated dogs. Int J Cardiol 45: 23-33. [Crossref]

41. Lyon AR, Rees PS, Prasad S, Poole-Wilson PA, Harding SE, et al. (2008) Stress (Takotsubo) cardiomyopathy - a novel pathophysiological hypothesis to explain catecholamine-induced acute myocardial stunning. Nat Clin Pract Cardiovasc Med 5: 22-29. [Crossref]

42. Benarroch EE (1993) The central autonomic network: functional organization, dysfunction, and perspective. Mayo Clin Proc 68: 988-1001. [Crossref]

43. White M, Wiechmann RJ, Roden RL, Hagan MB, Wollmering MM, et al. (1995) Cardiac fl-adrenergic neuroeffector systems in acute myocardial dysfunction related to brain injury: evidence for catecholamine-mediated myocardial damage. Circulation 92: 2183-2189. [Crossref]

44. Pierpont GL, DeMaster EG, Cohn JN (1984) Regional differences in adrenergic function within the left ventricle. Am J Physiol 246: H824-H829. [Crossref]

45. Kawano H, Okada R, Yano K (2003) Histological study on the distribution of autonomic nerves in the human heart. Heart Vessels 18: 32-39. [Crossref]

46. Mori H, Ishikawa S, Kojima S, Hayashi J, Watanabe Y, et al. (1993) Increased responsiveness of left ventricular apical myocardium to adrenergic stimuli. Cardiovascular Res 27: 192-198. [Crossref]

47. Novitzky D, Wicomb WN, Cooper DK, Rose AG, Reichart B (1986) Prevention of myocardial injury during brain death by total cardiac sympathectomy in the Chacma baboon. Ann Thorac Surg 41: 520-524. [Crossref]

48. Fripp RR, Lee JC, Downing SE (1981) Inotropic responsiveness of the heart in catecholamine cardiomyopathy. Am Heart J 101: 17-21. [Crossref]

49. Goldstein DS, Eisenhofer G, Kopin IJ (2003) Sources and significance of plasma levels of catechols and their metabolites in humans. J Pharmacol Exp Ther 305: 800-811. [Crossref]

50. Eldadah BA, Pacak K, Eisenhofer G, Holmes C, Kopin IJ, et al. (2004) Cardiac uptake-1 inhibition by high circulating norepinephrine levels in patients with pheochromocytoma. Hypertension 43: 1227-1232. [Crossref]

51. Farhan ML, Zinn A, Nabi U, Topalian S, Saeed W, et al. (2016) Overview of Takotsubo cardiomyopathy and role of multimodal imaging. Takotsubo Cardiomyopathy 91. 
52. Scantlebury DC, Prasad A (2014) Diagnosis of Takotsubo cardiomyopathy. Circ J 78: 2129-2139. [Crossref]

53. Kawai S, Kitabatake A, Tomoike H, Takotsubo Cardiomyopathy Group (2007) Guidelines for diagnosis of takotsubo (ampulla) cardiomyopathy. Circ J 71: 990-992. [Crossref]

54. Prasad A, Lerman A, Rihal CS (2008) Apical ballooning syndrome (Tako-Tsubo or stress cardiomyopathy): A mimic of acute myocardial infarction. Am Heart J 155: 408417. [Crossref]

55. Akashi YJ, Nakazawa K, Sakakibara M, Miyake F, Koike H, et al. (2003) The clinical features of takotsubo cardiomyopathy. QJM 96: 563-573. [Crossref]

56. Eitel I, von Knobelsdorff-Brenkenhoff F, Bernhardt P, Carbone I, Muellerleile K, et al. (2011) Clinical characteristics and cardiovascular magnetic resonance findings in stress (takotsubo) cardiomyopathy. JAMA 306: 277-286. [Crossref]

57. Afrasiabi M, Noroozian M (2010) Multimodality Imaging in Takotsubo Cardiomyopathy. In Lynch, Marvin (Ed), Takotsubo Cardiomyopathy, Middlesex, UK: Nova Science Publishers, Inc.

58. Opolski G, Pawlak MM, Roik MF, Kochanowski J, Scisło P, et al. (2010) Clinica presentation, treatment, and long-term outcomes in patients with takotsubo cardiomyopathy: Experience of a single cardiology center. Pol Arch Med Wewn 120: 231-236. [Crossref]

59. Citro R, Piscione F, Parodi G, Salerno-Uriarte J, Bossone E (2013) Role of echocardiography in takotsubo cardiomyopathy. Heart Failure Clin 9: 157-166.

60. Meimoun P, Passos P, Benali T, Boulanger J, Elmkies F, et al. (2011) Assessment of left ventricular twist mechanics in Tako-tsubo cardiomyopathy by two-dimensional speckle-tracking echocardiography. Eur J Echocardiogr 12: 931-939. [Crossref]

61. Andersson H, Atharovski KA, Christensen TE, Bang LE, Holmvang L, et al. (2012) How to distinguish takotsubo cardiomyopathy from acute myocardial infarction using multimodal cardiac imaging. Int J Cardiol 159: 73-74. [Crossref]

62. Nagai T, Konishi T, Arakawa J, Hisadome H, Tabata H (2014) Synchronicity of echocardiography and cardiac nuclear medicine in mid-ventricular ballooning syndrome: paired 'ring signs' on polar maps. Eur Heart J Cardiovasc Imaging 15: 947-947. [Crossref]

63. Kawecki D, Morawiec B, Monney P, Pellaton C, Wojciechowska C, et al. (2015) Diagnostic contribution of cardiac magnetic resonance in patients with acute coronary syndrome and culprit-free angiograms. Med Sci Monit 21: 171. [Crossref]

64. Ahtarovski KA, Iversen KK, Christensen TE, Andersson H, Grande P, et al. (2014) Takotsubo cardiomyopathy, a two-stage recovery of left ventricular systolic and diastolic function as determined by cardiac magnetic resonance imaging. Eur Heart $J$ Cardiovasc Imaging 15: 855-862. [Crossref]

65. Bashir A, Noroozian N, Steeds RP, Khan SQ (2013) Imaging features in Takotsubo cardiomyopathy. BMJ Case Rep 2013. [Crossref]

66. Ghadri JR, Dougoud S, Maier W, Kaufmann PA, Gaemperli O, et al. (2014) A PET/ CT-follow-up imaging study to differentiate takotsubo cardiomyopathy from acute myocardial infarction. Int J Cardiovasc Imaging 30: 207-209. [Crossref]

67. Bossone E, Lyon A, Citro R, Athanasiadis A, Meimoun P, et al. (2013) Takotsubo cardiomyopathy: an integrated multi-imaging approach. Eur Heart $J$ Cardiovasc Imaging 15: 366-377. [Crossref]

68. Ibanez B, Navarro F, Cordoba M, M-Alberca P, Farre J (2005) Tako-tsubo transient left ventricular apical ballooning: is intravascular ultrasound the key to resolve the enigma? Heart 91: 102-104. [Crossref]

69. Ogura R, Hiasa Y, Takahashi T, Yamaguchi K, Fujiwara K, et al. (2003) Specific findings of the standard 12-lead ECG in patients with takotsubo cardiomyopathy. Circ J 67: 687-690. [Crossref]

70. Abe Y, Kondo M, Matsuoka R, Araki M, Dohyama K, et al. (2003) Assessment of clinical features in transient left ventricular apical ballooning. J Am Coll Cardiol 41: 737-742. [Crossref]

71. Ito K, Sugihara H, Kinoshita N, Azuma A, Matsubara H (2005) Assessment of Takotsubo cardiomyopathy (transient left ventricular apical ballooning) using $99 \mathrm{mTc}$ tetrofosmin, 123I-BMIPP, 123I-MIBG and99mTc-PYP myocardial SPECT. Ann Nucl Med 19: 435-445. [Crossref]

72. Rivera AMC (2016) Reversible left ventricular dysfunction: A review of risk factors, management and prognosis. In Lynch, Marvin (Ed), Takotsubo Cardiomyopathy, Middlesex, UK: Nova Science Publishers, Inc.

73. Bietry R, Reyentovich A, Katz SD (2013) Clinical management of takotsubo cardiomyopathy. Heart Fail Clin 9: 177-186. [Crossref]
74. Bossone E, Savarese G, Ferrara F, Citro R, Mosca S, et al. (2013) Takotsubo cardiomyopathy: overview. Heart Fail Clin 9: 249-266. [Crossref]

75. Nieminen MS, Fruhwald S, Heunks LM, Suominen PK, Gordon AC, et al. (2013) Levosimendan: current data, clinical use and future development. Heart Lung Vessel 5: 227-245. [Crossref]

76. Padayachee L (2007) Levosimendan: the inotrope of choice in cardiogenic shock secondary to takotsubo cardiomyopathy? Heart Lung Circ 16 Suppl 3: S65-S70. [Crossref]

77. Shiomura R, Nakamura S, Takano H, Kato K, Inui K, et al. (2015) Impact of brain natriuretic peptide, calcium channel blockers, and body mass index on recovery time from left ventricular systolic dysfunction in patients with takotsubo cardiomyopathy. Am J Cardiol 116: 515-519. [Crossref]

78. Sharkey SW, Maron BJ (2014) Epidemiology and clinical profile of Takotsubo cardiomyopathy. Circ J 78: 2119-2128. [Crossref]

79. Silva MP, Vilela EM, Lopes RL, de Morais GP, Fernandes P, et al. (2015) Cardiogenic shock induced by Takotsubo cardiomyopathy: A new therapeutic option. Rev Port Cardiol 34: 695-e1-4. [Crossref]

80. Singh K, Carson K, Shah R, Sawhney G, Singh B, et al. (2014) Meta-analysis of clinical correlates of acute mortality in takotsubo cardiomyopathy. Am J Cardiol 113: 1420-1428. [Crossref]

81. Templin C, Ghadri JR, Diekmann J, Napp LC, Bataiosu DR, et al. (2015) Clinical Features and Outcomes of Takotsubo (Stress) Cardiomyopathy. N Engl J Med 373: 929 938. [Crossref]

82. Santoro F, Ieva R, Musaico F, Ferraretti A, Triggiani G, et al. (2014) Lack of Efficacy of Drug Therapy in Preventing Takotsubo Cardiomyopathy Recurrence: A Meta-analysis. Clin Cardiol 37: 434-439. [Crossref]

83. Szardien S, Möllmann H, Willmer M, Akashi YJ, Hamm CW, et al. (2013) Mechanisms of stress (takotsubo) cardiomyopathy. Heart Fail Clin 9: 197-205. [Crossref]

84. Castillo Rivera AM, Ruiz-Bailén M, Rucabado Aguilar L (2011) Takotsubo cardiomyopathy-a clinical review. Med Sci Monit 17: RA135-147. [Crossref]

85. Ionescu CN, Aguilar-Lopez CA, Sakr AE, Ghantous AE, Donohue TJ (2010) Longterm outcome of Tako-tsubo cardiomyopathy. Heart Lung Circ 19: 601-605. [Crossref]

86. Elesber AA, Prasad A, Lennon RJ, Wright RS, Lerman A, et al. (2007) Four-year recurrence rate and prognosis of the apical ballooning syndrome. J Am Coll Cardiol 50: 448-452. [Crossref]

87. Khalighi K, Farooq MU, Aung TT, Oo S (2015) Takotsubo cardiomyopathy: A long term follow-up shows benefit with risk factor reduction. J Cardiovasc Dev Dis 2: 273281. [Crossref]

88. Looi JL, Wong CW, Khan A, Webster M, Kerr AJ (2012) Clinical characteristics and outcome of apical ballooning syndrome in Auckland, New Zealand. Heart Lung Circ 21: 143-149. [Crossref]

89. Kurisu S, Inoue I, Kawagoe T, Ishihara M, Shimatani Y, et al. (2009) Assessment of medications in patients with Tako-tsubo cardiomyopathy. Int J Cardiol 134: e120-e123. [Crossref]

90. Parodi G, Bellandi B, Del Pace S, Barchielli A, Zampini L, et al. (2011) Natural history of tako-tsubo cardiomyopathy. Chest 139: 887-892. [Crossref]

91. Samardhi H, Raffel OC, Savage M, Sirisena T, Bett N, et al. (2012) Takotsubo cardiomyopathy: an Australian single centre experience with medium term follow up. Intern Med J 42: 35-42. [Crossref]

92. Cacciotti L, Passaseo I, Marazzi G, Camastra G, Campolongo G, et al. (2012) Observational study on takotsubo-like cardiomyopathy: clinical features, diagnosis, prognosis and follow-up. BMJ open 2: e001165.

93. Brenner R, Weilenmann D, Maeder MT, Jörg L, Bluzaite I, et al. (2012) Clinical Characteristics, Sex Hormones, and Long-Term Follow-Up in Swiss Postmenopausa Women Presenting with Takotsubo Cardiomyopathy. Clin Cardiol 35: 340-347.

Copyright: (C)2018 Albakri A. This is an open-access article distributed under the terms of the Creative Commons Attribution License, which permits unrestricted use, distribution, and reproduction in any medium, provided the original author and source are credited. 